\title{
EL TOR CHOLERA IN SINGAPORE
}

\author{
Lieutenant-Colonel P. J. BLACKBURN \\ M.A., M.B., B.Ch., M.F.C.M., D.P.H., D.I.H., D.T.M.\&H., R.A.M.C. \\ Headquarters, ANZUK Support Group *
}

SUMMARY: In 1972 the civilian population of Singapore suffered a small outbreak of EI Tor cholera. Preventive measures were undertaken by the ANZUK (Australian, New Zealand and UK) Force, and no cases occurred in servicemen or their dependants. The outbreak, however, had some interesting epidemological features not without relevance to military community and contrasted in some ways both with classical cholera and other outbreaks of El Tor cholera in South.East Asia.

\section{Introduction}

The 1972 cholera epidemic in Singapore was the most extensive recorded for fifty years. The Republic was declared an infected area on 11 th May, and remained so until the 19th October 1972. Three deaths occurred among the 114 confirmed cases, and 16 " carriers" were detected. No cases occurred amongst the ANZUK Force personnel or their dependants. The Singapore Armed Forces had one confirmed case.

\section{History}

In 1817 classical cholera began its spread from the Ganges and Brahmaputra deltas to cause successive world epidemics. The earliest record of its occurrence in Singapore was in 1841, and outbreaks then occurred in 1851, 1862, 1873-1874, 1895, 1900-1903, 1910-1914 (the latter averaging 170 cases yearly) and 1924-1928 (averaging 15 cases yearly). The sixth cholera epidemic subsided in the nineteen twenties, and from 1929 to 1941 there were no cases in Singapore (Singh 1972). Even during the Japanese occupation the only recorded outbreak occurred when a Japanese ship entered Singapore with the disease amongst the crew, of whom eight eventually died. This ship was quarantined at Seletar Base, but vegetables jettisoned were salvaged and consumed by Malay fishermen, who became ill some five days later. Cholera vibrios of similar strain were isolated from both the Japanese and Malay patients and identified as El Tor (Singh 1972). In Malaysia all pre-War epidemics were caused by the classical variety, but the El Tor biotype was occasionally isolated in sporadic cases. Both Malaysia and Singapore were free of epidemics in the post-war period until the beginning of the present seventh cholera pandemic, when El Tor cholera began its spread from its epidemic focus on Sulawesi in the Celebes in 1961. The name El Tor derives from the quarantine station at El Tor in Egypt, where in 1906 a haemolytic strain (a property now largely lost) of "paracholera". was isolated (World HIth Org. 1970). The presence in the then Dutch East Indies of this biotype was first reported in 1937, but it had remained quiescent with the exception of occasional sporadic spread to other Indonesian islands and Singapore (Felsenfeld 1963). The subsequent spread of El Tor cholera is shown in Figure 1 (Weekly Epidemological Record 1972). After the Sabah and Sarawak outbreak of 1961 it first appeared in Singapore in 1963. In that year there were 27 cases, with a further 24 cases

* Now Army School of Health, Ash Vale. 


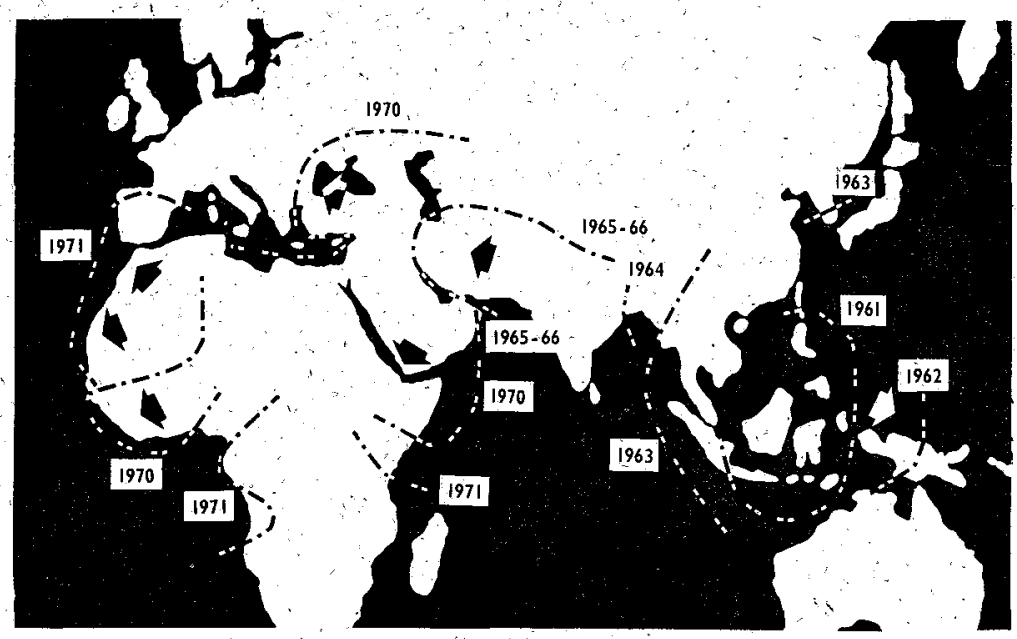

Fig. 1. Trend of global spread of cholera 1961-1972

in 1964. Outbreaks occurred in East and West Malaysia in 1963-1965, 1968-1970 and 1972, but Singapore was free from 1964 to 1972 .

\section{Singapore 1972 outbreak}

This began with the confirmation of two cases caused by vibrio cholera biotype El Tor, serotype Ogawa, on 11th May 1972. Both were in Chinese females, and no connection between the two was found. The first was a 21 year old girl with a two day history of diaorrhea and vomiting, who came to Singapore originally from Malacca (an infectéd area) but who had not visited or received any friends or relations from there since 24th March. Her accommodation had piped water and water-borne sanitation. The second case had a similar two day history, but lived in a tenement' with community bucket latrines; she had not been beyond her immediate environment. All home contacts of these cases were isolated, and no diaorrhea cases were found in the neighbourhood. A total of six carriers were found in the close contacts of these cases. This early success in detecting carriers in the personal contacts of cases was not repeated; in spite of considerable efforts only 16 carriers were found in the whole epidemic. The explanation for this is obscure. Cases continued to occur at the rate of two or three a day, and the first death occurred on the 12th May in a man of 68, within a few hours of his admission. The diagnosis was made post mortem. The further course of the epidemic is shown at Figure 2, with a peak at the end of May followed by a slow decline in incidence, with cases detected becoming progressively more widely spread.

Several factors became clear as investigation by the Singapore Public Health authorities proceeded. Most cases had no obvious connection with each other, were occurring mainly in Chinese, (Progress Reports 1972, restricted circulation) (Table I), in adults, and were spread over a wide geographical area. There was no consistent increase in other notifiable gastro-intestinal illness (Table II). (Singapore Bulletins of Infectious Disease 1972). This was in contrast to the experience in Malaysia, 1961-71, where distribution by ethnic group was proportional to the population groupings (Singh 1972) and to the concurrent increase in both amoebic and bacillary dysentery in the Sarawak outbreak (Report 1965). 


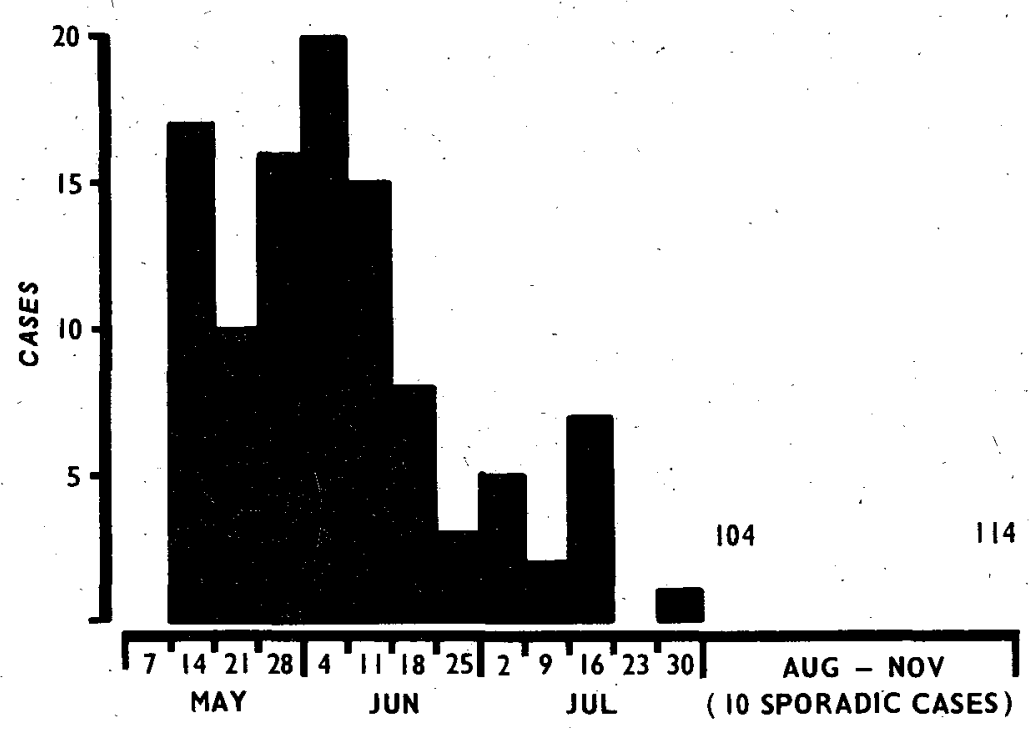

(Figs. 1 and 2 produced by The Department of Medical Illustration Manchester Royal Infirmary)

Fig. 2. Cases of cholera by date of onset. Singapore 1972

Table I

Cholera cases by race, Singapore 1972

\begin{tabular}{|c|c|c|c|c|}
\hline Race & $\begin{array}{l}\text { Number of } \\
\text { cases }\end{array}$ & $\begin{array}{l}\text { Percentage of } \\
\text { total cases }\end{array}$ & $\begin{array}{l}\text { Population of } \\
\text { Singapore June } 1972\end{array}$ & $\begin{array}{l}\text { Percentage of } \\
\text { total population }\end{array}$ \\
\hline $\begin{array}{l}\text { Chinese } \\
\text { Malay } \\
\text { Indian } \\
\text { Other }\end{array}$ & $\begin{array}{r}110 \\
2 \\
2 \\
0\end{array}$ & $\begin{array}{l}96.16 \\
1.92 \\
1.92 \\
0\end{array}$ & $\begin{array}{r}1,634,600 \\
323,200 \\
149,600 \\
40,000\end{array}$ & $\begin{array}{l}76.1 \\
15 \\
7 \\
1.9\end{array}$ \\
\hline Totals & 114 & 100 & $2,147,400$ & 100 \\
\hline
\end{tabular}

Table II

Occurrence of enteric fever. Singapore from April 1972

\begin{tabular}{c|c|c|c|c|c|c|c|c|c}
\hline April & May & June & July & August & September & October & November & December & Total \\
\hline $17(9)$ & $19(9)$ & $9(15)$ & $12(9)$ & $5(11)$ & $5(21)$ & $5(14)$ & $5(12)$ & $7(10)$ & $84(10)$ \\
\hline
\end{tabular}

Notes. Figures in brackets are 1971 totals. Dysentery is not notifiable, but 3 deaths occurred in 1972 and 7 in 1971.

The distribution of cases by age and sex is shown at Table III. It is noteworthy that the majority were over the age of 35 , and no cases occurred in children under 5. Sixty-four cases were classified as severe, 29 as moderate and 21 as mild: among those most severely affected were patients with complete or partial achlorhydria (six had had partial gastrectomies), with an underlying illness such as a tuberculosis, or who were opium smokers (where the drug masked the symptoms). 
Table III

Cholera cases by age and sex. Singapore 1972

\begin{tabular}{l|c|c|c}
\hline \multicolumn{1}{c|}{ Age group } & Male & Female & Totals \\
\hline Up to Five years & 0 & 0 & 0 \\
Six to Fifteen years & 4 & 4 & 8 \\
Sixteen to Twenty-five years & 10 & 3 & 13 \\
Twenty-six to Thirty-five years & 9 & 7 & 10 \\
Thirty-six to Forty-five years & 38 & 9 & 18 \\
Forty-six years and over & 64 & 27 & 65 \\
\hline Totals & & 50 & 114 \\
\hline
\end{tabular}

The problem of identification of a common vehicle of infection was not solved. Water supplies were exonerated both on direct examination and on epidemiological grounds. Some widely sold food or drink, possibly favoured by the Chinese element in the population, was thought to be a possibility. Investigation of food and drink sold on the innumerable stalls (a common, often exclusive, source of food for many Singaporeans) showed widespread contamination with faecal E. coli (357 of 641 samples examined), but no cholera vibrios. Most food handlers selling contaminated food had rectal swabs taken, but no cholera vibrios were isolated. Faecal E. coli, but again no cholera organisms, were isolated from the centres of apparently intact water-melons, probably due to the practice of injection of sweetened water to increase weight and attractiveness.

Before the epidemic subsided in October two more deaths had occurred, one in a debilitated woman of 89 years and one in a woman of 45 who became ill with diarrhoea and vomiting on one of the Southern Islands, and died after five days without seeking medical assistance. Extensive investigation (510 persons of a total population of 588 being examined) of the population of this small island, which the patient had not left for 4 months, failed to reveal any further cases or any cryptic carriers.

A further isolated case was confirmed bacteriologically on 30th January 1973 (El Tor, Ogawa strain). No further cases developed and no carriers were discovered: Two hundred and nineteen swabs from 54 persons (contacts and carriers) were negative for cholera, as were food samples. Of the latter, however, 16 were positive for faecal E. coli. (Daily progress reports 1973). The Republic wás again declared free of infection on February 1973. Measures taken by civilian authorities to stem the disease were naturally greatly hampered by the unknown nature of the vehicle of infection; however a programme of health education on the general lines of correct food hygiene practice and sanitary hygiene was commenced, making use of all the media. Boiling of drinking water advocated; at first sight this was an anomalous measure in view of the good piped supply, but was considered necessary as in some rural areas water for individual households is collected from a central tap and stored before use in a variety of receptacles. Mass vaccination of the civil population was not practised, but vaccination was available at Government Clinics on demand. All contacts were vaccinated as a matter of form. By the 19th October some 105,689 persons had rectal swabs (mainly single) examined, and one typhoid carrier was found. The practical difficulties of mass multiple sampling were considered by the authorities to be too great, although many close contacts of cases 
were admitted for investigation and-had several bacteriological examinations. Certainly the widespread and prolonged appearance of sporadic cases would suggest a reservoir of undiscovered infection, and possible intermittent excretion.

Preventive measures by the ANZUK force

The ANZUK Force in Singapore comprised some 5,000 servicemen and 7,000 dependants widely dispersed round the island, with many local civilians both as official employees and private domestic servants. Eating at food stalls is one of the tourist attractions in Singapore, and is practiced by ANZUK personnel; fresh local fruit (including melon) and vegetables are popular items in messes and homes.

All ANZUK Units and attached civilian organisations were advised on precautionary measures, for action and for promulgation to families. These were basically a reiteration of current advice (through ANZUK Base Standing Orders (Health)) on personal hygiene, food hygiene; including the sterilisation of fresh fruit and vegetables by immersion in Water Sterilising Powder (calcium oxychloride and calcium oxide) solution, the avoidance of certain local fruits (including melons), the avoidance of eating at street food stalls, the early reporting of sickness (especially in food handlers), vaccination, and, latterly, the treatment of drinking water. This last measure was at first sight an unnecessary precaution, and indeed resulted in many not unforeseen practical difficulties. It was promulgated following similar advice to the Singapore population, and in view of the extensive building works in many areas of Singapore and the fact that the reticulations of some pre-war barracks had given trouble in the past. The rationale was therefore purely precautionary, and as the outbreak continued it became quite clear from the occurrence and distribution of cases that it was not water borne. However, as described later, some accidental pollution of water supplies was detected and to some extent vindicated the decision. Units were advised on the use of water sterilising powder, and Sodium Hypochlorite solution 1 per cent "Milton " was issued to families in gallon containers, with appropriate instructions.

The vaccination state of ANZUK Servicemen was good. Some families had allowed their certificates to lapse and they were quickly brought up to date. Medical centres re-vaccinated all comers or demand at any time. No mass re-vaccination was considered either necessary or desirable. Vaccination was performed intradermally in accordance with current instructions (Memorandum on Immunological Procedures 1968) although advice was sought from Ministry of Defence (UK) in view of recent criticism (McBean et al 1972) of its efficacy. The Army Pathology Advisory Committee advised that intradermal injection with a needle and syringe should continue to be an acceptable alternative to the subcutaneous route.

During the early stages of the outbreak all the Hygiene and Malaria Control Section uniformed personnel were engaged in visiting units and other ANZUK organisations to advise on the implementations of the published precautions. In addition all local food vendors in ANZUK areas, including service clubs, were revisited (they being already subject to registration and inspection).

Routine water sampling from all ANZUK installations and married quarters had been undertaken from the setting up of the Force, and this was increased as a precautioary measure. Results were initially entirely satisfactory, but beginning on 19th May some twenty-one tap water samples from various married quarter areas in the south of the 
island were reported on by the laboratory at the ANZUK Military Hospital Changi as "suspicious" or "unsatisfactory", with growth of coli-aeroggenes organisms ranging from 4 to 10 per $100 \mathrm{ml}$. Eijkman tests were consistently negative. Not surprisingly no residual chlorine was detected at the tap for any samples taken. Action was taken to convey our misgivings to the Singapore Government through staff channels and detailed reports sent directly to the Public Health Division and to the Water Authority responsible (Public Utilities Board, Singapore). Remedial action was put in hand by the latter, and the importance of domestic treatment was re-stressed to the occupants. By the end of June samples showed much improvement and a chlorine residual became detectable at the tap. The cause of this situation was established to be work on the mains in the areas affected, notably the installation of water meters. This had no relevance to the cholera outbreak in Singapore as a whole, but was a source of anxiety until corrected.

ANZUK schools had few facilities for treatment of their drinking water, and children were advised to bring their own drinks (schools close during the afternoon, so no lunches are served). Later suitable containers were made available and water treated on the spot. Two schools had arranged educational trips to Malaysia (both to other locally infected areas), and these were deferred on medical advice.

Throughout the epidemic close liaison was maintained, with the Department of Quarantine and Epidemiology. Public Health Division, Singapore and confidential daily bulletins received.

\section{Discussion}

The present pandemic of El Tor cholera has shown, in its manifestation in Singapore in 1972, that problems of control differ from that of classical cholera, and yet the clinical disease can be equally severe. It would appear that without the vigorous institution of modern treatment mortality rates would approach classic levels. Accordingly the Services must view the disease with concern. In Singapore the outbreak occurred without warning, and continued for six months with no firm identification of the vehicle of infection despite assidious investigation. This was in a country which had made great efforts to improve the environment,' with water supplies which are almost exclusively piped and municipal, much of the sanitation modern waterborne, few flies, and with a very extensive urban renewal programme cited as a model for Asia. In general some of these favourable factors may have been counteracted by the incomparable increase in both the volume and speed of international travel.

The nature of the infective organism is relevant, and although the presence of healthy carriers in endemic areas of classical cholera was shown by Bencic and Sintra (1972); Mosley, Bart and Sommer (1972) estimate for every case of El Tor cholera there are 20 to 40 excretors, who are either symtomless or suffer from mild diarrohea: Principles and Practice of Cholera Control (1970) gives ratios of mild or inapparent cases to severe as 5-10 to 1 and 25-100 to 1 for classical and El Tor varieties respectively. These ratios could not be confirmed in the Singapore outbreak, but would account for the epidemiological picture seen. Viability of the El Tor strain is greater both in foodstuffs and in night soil. Transmission from person to person wás shown in the Philippines outbreak (Philippines Cholera Commission Report 1970), and there the sporadic picture changed dramatically to an explosive outbreak when the water supply became contaminated. 
It is of interest that Felsenfeld (1963) noted that original spread in the Western Pacific in 1961 did not differ either clinically or epidemiologically from other (classical) cholera outbreaks. It attacked poor and undernourished people living in insanitary conditions, and spread along coastlines, and, to some extent, along inland waterways. The Singapore outbreak has been shown to be in direct contrast to this.

It is therefore clear that to assume communities such as static service populations who have modern sanitary facilities and treated water are, per se, invulnerable is unsafe; person to person spread, the occurrence of symptomless carriers, the formation of aerosol from water closets, communal feeding in messes, access to civilian food of doubtful cleanliness, and the very variable protection of the available vaccine, all contribute to a potentially serious situation. Under exercise conditions in tropical countries, especially where local staff are recruited for the rear and echelon areas, the problem is compounded.

The preventive measures to be taken are standard Army Health teaching for the control of gastro-intestinal disease, and in Singapore in 1972 these received additional impetus due to this occurrence of cholera among the civilian population. These measures have been detailed elsewhere (Manual of Army Health 1965, Control of Communicable Diseases in Man 1965) but in summary comprise health education in personal and food hygiene, supervision of personnel, of food processing, presentation and serving in kitchens and messes, protection and purification of water supplies, early reporting of cases and their immediate investigation, vector control, and sanitary disposal of faeces.

The occurrence of this outbreak underlined the changing pattern of the disease. It appears to have adapted to survival in a modern urban environment, and showed special features even for an El Tor epidemic.

Cholera has now become at least temporarily entrenched over a very wide area, representing a constant threat to the rest of the world (Official Record, World Health Organisation 1973) and it seems possible that in the future it may become, for the Services, a continual hazard in the occurrence of sporadic cases, even if it is unlikely to re-occur in the large scale epidemics of past centuries. However it is a potentially serious disease, although eminently treatable, and its apparent change to a more cryptic nature will make the hazard to troops on operations or exercises more important. This underlines the continued necessity for preventive measures, which, apart from the specific vaccination, are common to the control of all excremental disease.

\section{REFERENCES}

Bulletin of Infectious Diseases (1972). Ministry of the Environment, Republic of Singapore (restricted circulation).

BENCIC, Z. and SinTRA, P. (1972). Int. J. Epidem. 1, 12.

Control of Communicable Diseases in Man (1965). The American Public Health Association.

Felsenfeld, O. '(1963). Bull. Wld Hith Org. 28, 289.

McBean, A. M., Agle; N. A., CompaOne, R., Foster, S. O. and McCormack, W. M. (1972). Lancet $1,527$.

Manual of Army Health (1965). Army Code No. 10157. H.M.S.O. London.

Memorandum on Immunological Procedures (1968): JSP 311 as amended 1972. H.M.S.O. London.

MOSELY, W. H., BART, K. J. and Sommer, A. (1972). Int. J. Epidem. 1, 5.

Official Records of the World Health Organisation (1973). 205, 27.

Philippines Cholera Commission Report (1970). Bull. Wld Hlth Org. 43, 413.

Progress Reports Cholera Situation (1972, 1973). Environmental Public Health Division. Republic of Singapore (restricted circulation).

Report on Cholera Outbreak in Sarawak 1961 (1965). Government Printing Office. Sarawak.

SinGH, A. B. (1972). Med. J. Malaya 26, 149.

Principles and Practice of Cholera Control (1970). Wld Hlth Org. Publ. Hlth Pap. 40

Weekly Epidemiological Record (1972). 47, 281. 